\title{
FUNdamental Developments in the Undergraduate Organic Chemistry Laboratory
}

\author{
Monika R. Snowdon ${ }^{1 *}$ \\ ${ }^{1}$ Department of Chemistry, University of Waterloo, Waterloo, Ontario, N2L 3G1 \\ *Corresponding Author: monika.snowdon@uwaterloo.ca
}

\begin{abstract}
The undergraduate lab for organic chemistry varies from campus to campus. However, the consensus from students does less so. In general, organic chemistry is one of the most daunting course for science undergraduate students, and the content presented in the corresponding laboratories of these courses can be equally difficult. There has been a shift towards modifying the content of the organic chemistry lab to make it an improved learning experience for the students, such that schools are graduating better chemists, as ultimately, the students are retaining the skills and information more efficiently. This study reviews some of the past decades improvements towards modifying the organic chemistry undergraduate lab experience to make organic synthesis a more engaging and interesting topic for students.
\end{abstract}

\section{Introduction}

Engagingly teaching is an art form and is difficult to quantify. Instructors must facilitate knowledge construction while gauging student interest and the willingness to engage, whether the students are present in the teaching environment willingly or not. Managing this successfully can be daunting and difficult. Instructors are faced with a teaching context where diversity and competing priorities are presented at many levels, and undergraduate students are in the process of learning how to balance adult life, including financing their education and other stressors while navigating the new terminologies and ways of being that come with every degree course. Some science courses like organic chemistry have a reputation for being gruelling and are 
considered to provide an overwhelming experience for most students. The informal consensus for organic chemistry among undergraduates is that it is difficult. This consensus equally goes for instructors, who consider that teaching organic chemistry is also quite difficult, and some have spoken at conferences in that organic chemistry teaching is in a state of crisis as students are bombarded with the material of this "new language.” Work by Szu et al. (2011) has shown that even high GPA students become low performers when delving into organic chemistry for the first time. Therefore, there is much to consider in the exposure, testing, retention and overall teaching of organic chemistry among the teaching community when educating the undergraduate cohorts.

Typically, in organic chemistry, the course component is supplemented by a hands-on laboratory experience in which the students must learn not only the reasoning behind the reactions but also how to safely and adequately perform them. Additionally, the correlation between real-world lab work and the laboratory course is also often misinterpreted or mismatched. Because for the most part, teaching experiments are designed to be simplistic enough yet the faculty's intentions are to develop critical thinking skills and techniques, whereas students want good grades and to finish the lab early/on time (Santos-Díaz, Hensiek, Owings, \& Towns, 2019). Therefore, as a result, students are evaluated in a traditional teaching lab in ways that do not reflect the value of actual lab skills as required in the real world (Santos-Díaz et al., 2019). The key problems are therefore twofold. First, there are inefficient and outdated teaching methods in the organic chemistry lab that fail at building confidence in the student's new knowledge, and second, traditional strategies are rendering students unequipped to connect theory and practice so they do not recognize the role of chemistry in shaping their worldview as undergraduates (Fung \& Watts, 2019). Hence, some changes in teaching approaches are being 
promoted among the chemistry educational community to improve student learning in the organic chemistry laboratory.

This work explores various research studies focusing on recent developments for improving organic chemistry approaches in the laboratory, as this is the setting that is the most interactive and engaging throughout the chemistry degree experience. Though there are many alternatives for improved and engaging laboratory practice, the examples covered here are used to discuss easy to apply activities and experiments and include suggestions to modify traditional delivery to create an enjoyable learning environment. This paper is structured by firstly introducing studio-based learning and problem-based learning as they were the most prominent teaching directions in the current literature for organic chemistry undergraduate laboratories to changing the traditional lab format. After the teaching methods are introduced, activities and adaptations from the literature will follow, showing different modifications that can occur from the introductory to more advanced levels, i.e. beginner/first year to upper year/final year undergraduate. Prospects will be detailed on these teaching improvements in making the organic chemistry lab from the perspective of an experienced teaching assistant in this field as well as comments on the practicability of the work.

\section{Approaches to lab teaching: Traditional to Expository labs}

Research surveys conducted for organic chemistry undergraduate courses have depicted that students care more about obtaining good marks and finishing the lab early - known as affective goals - whereas instructors tend to value core knowledge while developing critical thinking and life-long learning techniques to prepare students for the workforce (Szu et al., 2011). Consequently, from the very start of the term, there is a mismatch in laboratory course 
expectations. Studies have also shown that many students only care about their final products, and it is difficult for them to not focus solely on their results (Popova \& Bretz, 2018). Further, the students have described the chemistry lab experience to be an

"(The lab is an) isolating and ineffective use of learning time and (we) fail to see how the experiment is relevant (to the course)"

Reid \& Shah, 2007, p.2

This statement also depicts that there is a lack of perceived relevance from the student perspectives, which in turn affects their overall motivation for the overall lab. However, these problems can be circumvented by the instructors providing clear learning objectives and modifying the lab evaluation and report structure by incorporating a wide range of activities to help the students, which in the end can develop better chemists (Carmel et al., 2019).

Though different strategies can be taken toward improving the traditional lab teaching format, studio-based and problem-based approaches discussed in this section of the paper have been shown to be very effective (Collison, Cody, Smith, \& Swartzenberg, 2015). Some educational researchers advocate a complete re-evaluation of organic chemistry lab teaching (Carmel et al., 2019). Regardless of the extent of proposed instructional change, all these scholars agree that the traditional "cookbook" chemistry lab format is ineffective for teaching the new wave of organic chemists $y$. The expository or otherwise known as the traditional/cookbook lab delivers the content through pre-lab readings, a pre-lab lecture at the beginning of the lab slot. Students execute the experiment that has been detailed for them in a step-by-step manner, with the number of reagents and what to do already outlined for them. The learners must simply follow the steps and collect their data. The work should be reported in a laboratory notebook - a 
skill that is meant to teach students the value of replicability - such that others may replicate the results based on the annotations.

The expository lab requires minimal knowledge in order to perform the lab appropriately as all the instructions are included in detail. This can be hindering to the learners as the lab is one of the only locations where they can perform the reactions they are learning in the lectures and witness first-hand how chemistry works. Therefore, improvements are needed to make the material engaging while also teaching the students valuable skills such as information literacy and relying on their knowledge. To help students develop these skills, many university instructors, including those in the field of science, are implementing student-centered approaches to teaching and learning. 'Student-centered' refers to developing the autonomy and independence of the learner. Educational research has demonstrated that the standard lab manual and session are setup to thwart the problem-solving progression along with decreasing the need for practicing high level cognitive abilities such as analysis and evaluation (Domin, 1999; Russell, Mason, Bean, \& Murphree, 2014). The schematic diagram in Figure 1 by Russell and colleagues (2014) depicts that following step-by-step lab instructions requires some degree of understanding of the material but can get by with limited comprehension and knowledge. If the lab takes on a more self-directed path, where students must relay on knowledge they already know or course readings, they develop higher order cognitive abilities such as analytical skills and more mature synthetic ones as well as they would be relaying on their own abilities a bit more, as they would in a real-world lab. 


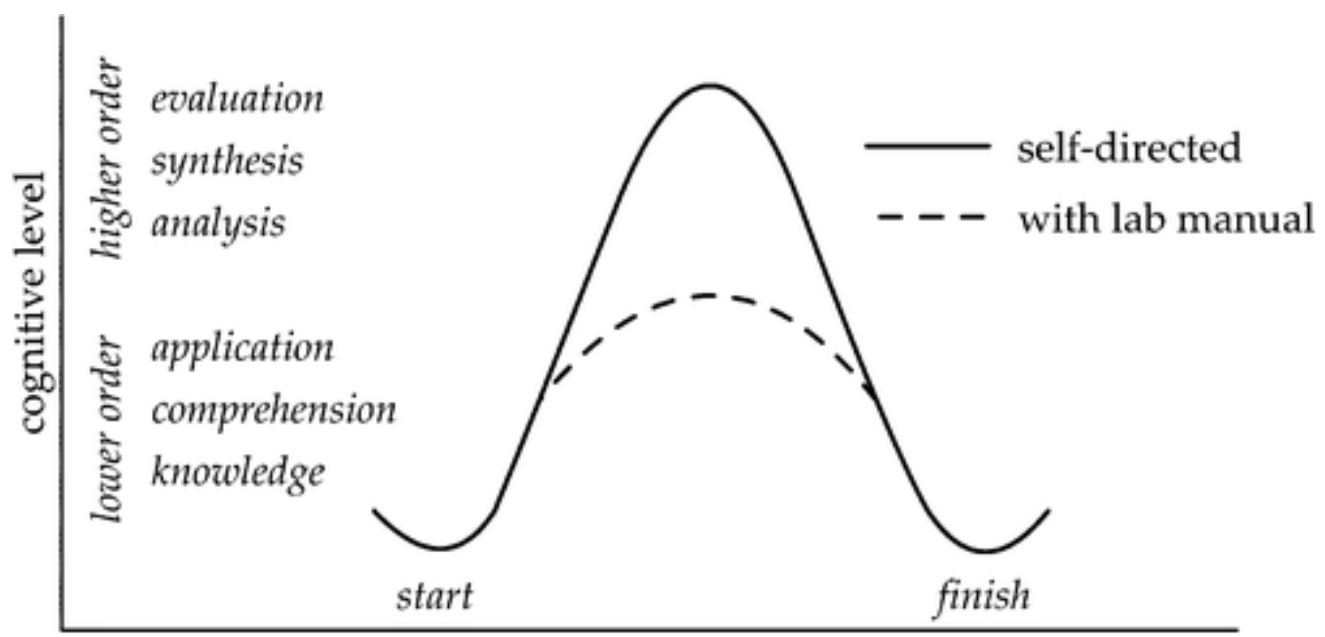

laboratory activity

Figure 1. Comparison diagram for chemistry lab activities using a lab manual versus self-directed student-centered learning. The higher the curve, the higher the cognitive abilities of the learners are being tested and developed. (Russell et al., 2014)

Recent work by Fung \& Watts (2019) argues that the undergraduate chemistry laboratory should put learning into the context of Kolb's experiential learning cycle that has four-levels of learning and combined with four level distinct learning styles. This puts the focus on the learning process for the students and not just the outcomes. The integration of Kolb's experiential learning can be done in a variety of different ways, including different learning models and activities that will be addressed in this manuscript.

The main hindrance to the overall implementation of improved teaching methods in the lab is the increase in time needed for the activities and learning, and training for the faculty and teaching assistants. A brief overview of studio-based and problem-based approaches are outlined below as they present important suggestions for implementing different activities and experimental changes. A discussion of their potential also is addressed from the perspective of a current organic chemistry teaching assistant (TA). 


\section{Studio-based approach}

The concept of studio-based learning (SBL) typically refers to an environment where students work on a project or a problem through activities with the teacher monitoring and answering questions as if they were in an art studio. One of the many benefits of SBL is that other students may overhear feedback and comments given to their peers - thus correcting misconceptions from students who are too nervous or unaware of their issues. The learning outcomes of SBL are to enable the students to engage creatively and authentically such that they can get immediate feedback on their work from the instructor or their peers. Although traditionally utilized in arts and architecture, there is a movement towards incorporating SBL into the science, technology, engineering, and mathematics (STEM) as this kind of teaching can be applied in any field with a few modifications such as a bit more of a time commitment for activities and teamwork (Connor, Karmokar, \& Whittington, 2015). Examples of SBL in the organic chemistry undergraduate lab included several step-by-step procedural modifications as exemplified by Ong, Chang \& Hoang (2018) for Sonogashira coupling where the students responded positively to the change. Students worked in groups to investigate which method was the best for large-scale production. Through this practical scenario, students learned to conduct a literature search, select procedures, practice their synthesis skills, and evaluate their results in a real-world context. Student feedback and comments were very positive, such as:

"Perform your own procedure based on research and choosing based on understanding. Most fun and excitement experience in the lab.”

"I like that we were able to work as a group and share our observations and results." 
Another strategy is suggested by Collison and colleagues (2015) where students adapt what appears to be a doodling activity on the first lab day that is transformed into teaching students how to use a lab manual effectively. Regardless if the activities are simple or more advanced such as in Ong's work, the increased emphasis on hands-on assistance and experiences is instrumental in the creation of better chemists (Latimer et al., 2018). The "studio-based" approach incorporates student-centered activities in order to contextually introduce undergraduate students to their first semester organic chemistry laboratory.

The key take-aways from incorporating SBL were observed to be increased collaboration and thought sharing between groups of students, not just within partners/friends. As well, the learners had a greater appreciation for the skills that should be incorporated to make them into improved chemists once they enter the workforce, as well as get a sense of awareness of the level of responsibility and time it takes to properly conduct chemical reactions.

\section{Problem-based learning approach}

Frequently when discussing improvements to teaching and learning, problem-based learning (PBL) is at the forefront of activities that an educator can use to make the classroom or lab room more interactive and authentic. The PBL technique offers a great alternative to traditional didactic teaching in science and is just now starting to surface as a method for chemical lab teaching. The concept stems from case-based learning (Herreid, 1997), a strategy successfully applied to other disciplines such as biochemistry (Kulak \& Newton, 2014) and medicine (Norman \& Schmidt, 2000). The PBL is much more developed as a teaching strategy than SBL as evidenced by the high quality of literature published since the 1970s and surging at the start of the millennia as shown in Figure 2. 


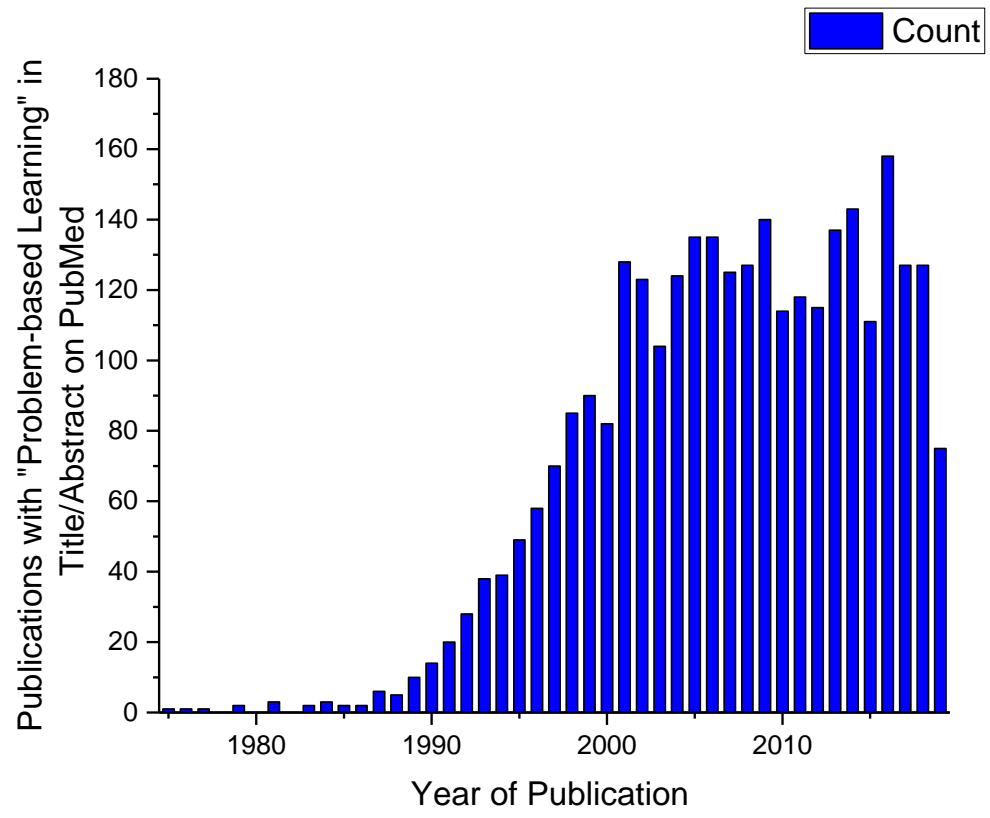

Figure 2. From search query "Problem-Based Learning" being found in either the abstract or title of a journal on the PubMed search engine. The amount of times PBL appears in a literary source per year of publication, beginning in 1975 to 2019.

Further limiting the journal search for chemistry-specific PBL studies from 2009-present still garners a significant count of over 800 publications. However, organic chemistry in lab learning using PBL is just beginning. The PBL method is used to avoid the recipe/cookbook style of laboratory learning so that students can learn and apply standard lab practices. Work by Fung \& Watts, Collison, Connor and others is trying to combat the "Pass and Forget" style of learning that is plaguing the teaching lab. 
Integrating PBL in the organic lab does equate to more time spent in lesson planning for the instructors as well as a complete revamping of how the lab manual and overall lab is set up. A typical undergraduate laboratory in organic chemistry is often that the students are given a molecular reaction and they must fulfill its complete synthesis in either a 3- to 6-hr lab period. In a PBL-based course, the students would have to be additionally encouraged to develop the synthesis of the molecule and attempt to solve the components with information they possess from the corresponding organic class lectures. The students must learn how to use and appreciate the information they already have and then to apply it. The learners must also identify what they need to learn to better understand the problem and how to solve it. Examples of integrating PBL in the organic lab have been developed by Flynn \& Biggs (2011), Shultz \& Li (2015) and Ong et al. (2018). The work of these various works will be further discussed in the following sections as they are great examples of incorporating PBL into the teaching labs, for the more advanced levels of students (third/forth year undergraduate).

\section{Innovative In-lab Activities}

This section of the paper will discuss different learning activities that have been developed and tested specifically with the undergraduate organic chemistry lab in mind. These are recent examples of changes that instructors have taken to develop the organic chemistry lab experience and create knowledgeable chemists.

One of the primary issues undergraduate students face when first encountering the organic chemistry lab is organizing the material that belongs in their laboratory notebook. Learning the skills for organization and retention of information is quintessential for success in the course. Usually, students have minimal practice with filling out a lab notebook and do not 
have a clear understanding of record keeping and the overall scientific method. The importance of this skill must be emphasized within the first lab-day. Implementing activities from the very first lab can help the learners put their knowledge into context. In the following example, SBL is used. The studio model on the first day integrates the learning outcomes of the course along with lab safety and the maintaining of a professional lab notebook. The developed FACE activity is illustrated in Figure 3 and is used to emphasize the importance of disseminating and annotating information in a lab notebook (Collison et al., 2015).

The activity helps with noticing variables or vagueness when writing up instructions, as well as the care the students should take when drawing conclusions. The FACE activity works in the following manner: each student inscribes their name on the top of a piece of paper and draws a caricature face. This is titled original. A second paper is then circulated, and each student writes a list of instructions to guide someone else to draw the same face as the original, but without ever being able to see the original face. Only the instructions are given out randomly with a third clean sheet labelled copy. The students most follow their given instructions to draw a proper face. All the copies are then matched to their original counterpart. This activity is akin to being able to reproduce reactions in the lab. As per Figure 3, this is a good activity for relaying the message of details and specifics. The students were then asked the following week later in the lab to replicate the face without any instructions as this would be representative of not writing in the lab notebook the procedure as it happens and waiting to get home to do it a week later (Collison et al., 2015). 


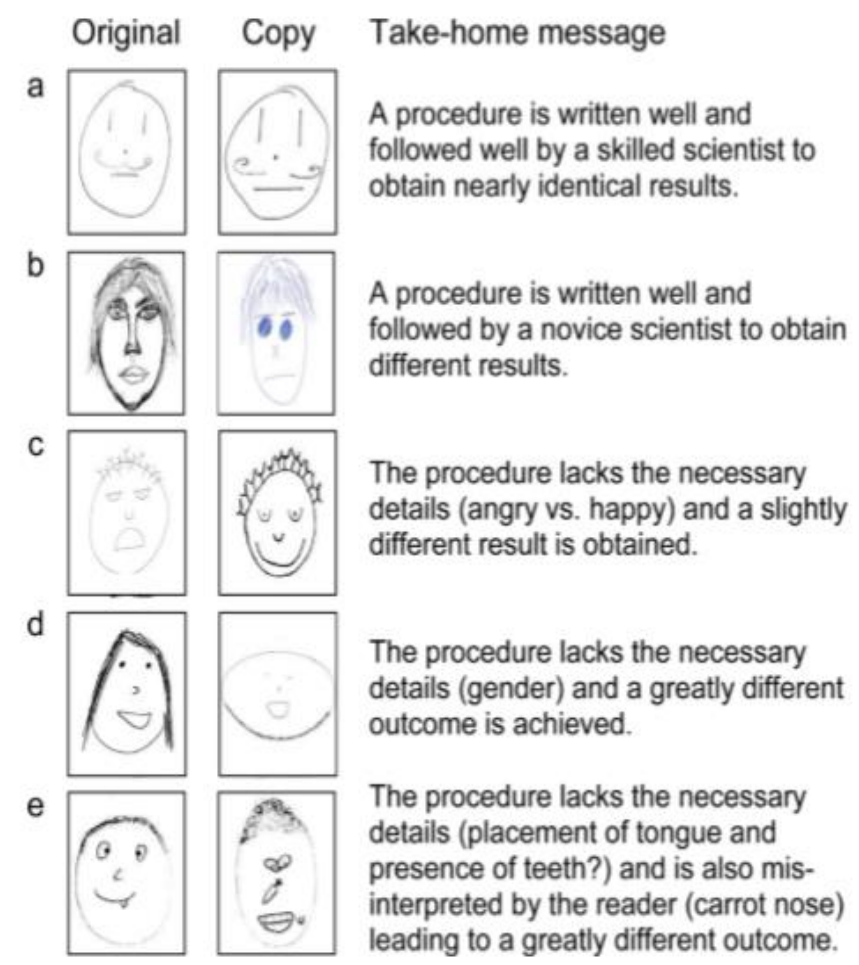

Figure 3. Samples of the outcomes of the FACE learning activity as developed and illustrated by Collision et al. (2015). The activity is an SBL approach to demonstrate the effectiveness of keeping a proper laboratory notebook in the organic lab.

Previous SBL examples in organic chemistry by Collison, Cody \& Stanford (2012) included a series of worksheets for proper execution of SBL learning. These worksheets address the key preliminary reactions students are first introduced to and are probably the most important (commonly known as $\mathrm{S}_{\mathrm{N}} 1-\mathrm{S}_{\mathrm{N}} 2$ ). The results from using SBL versus the standard lab format (expository format in their study) determined that the students in the studio lab observed $20 \%$ higher retention rate of the material when having to take a long-term retention quiz (8 weeks after material first presented). These findings demonstrate the importance that changes do need to be made in the organic lab for students to remember the material they are learning and be knowledgeable chemists once they finish their degrees. The results also show that guided-inquiry is useful for further promoting that students have knowledge and guides them on how to use it as opposed to giving them all the details and information and just rushing to finish the lab on time. 
Another teaching activity for the introductory organic chemistry lab can be done by incorporating the flipped classroom approach utilizing technology for pre-laboratory activities (Chaytor, Al Mughalaq, \& Butler, 2017). Teaching videos of the glassware setups where filmed prior to the start of the term, such that they were recent and, in the location that the students would doing the experiments in. The videos where created for both the organic chemistry I and II lab courses and would also contain some information about the experiment itself, the theory and the importance of the chemistry occurring. This was done in order to encourage the learners to ask "Why" questions instead of simply following the steps given to the in lab (i.e. following a recipe as in the traditional cookbook model). The videos where no more than 10 minutes in length and were created to give students a general idea of what they will be doing through various visual demonstrations.

Once the videos were implemented, the students were surveyed about their experience with them and how the videos helped their understanding of the material. Many of the learners reported that the videos aided them in being better prepared to conduct their experiments as well as understand the concepts. The videos also helped the students to identify the reactions and relate them to their lectures. To add, the delivery of the material was observed to be much more consistent over the course of the many lab sections even though various TAs where used (Chaytor et al., 2017). However, it is important to note that approximately $20 \%$ of the students did not watch the videos, and $4 \%$ of students did not find the videos useful. This can be a challenge when integrating technology-based teaching approach as students can easily find distractions or excuses to not dedicate 10 minutes towards their organic chemistry course. Nevertheless, the remaining $76 \%$ of students that watched the videos and benefited from them gave overwhelming positive feedback. 
An interesting idea would be to discuss or watch the videos in groups and then have the students discuss important information with each other or with the instructors through an SBL model. Evidence for using videos as pre-laboratory learning tools was analyzed by Moozeh and colleagues (2019) who found that students had an increased motivation for the laboratory experiments and could better relate to the theory and scientific practices that they had to execute. By understanding the usefulness of the material, students were then more motivated to learn and accomplish their chemistry (Moozeh, Farmer, Tihanyi, Nadar, \& Evans, 2019). Formative assessments were included at the end of the video without a time limit. Students responded well to this approach as they were not under pressure and could go through the material and take time to process it. The assessments were marked by the computer system immediately, so there was no need for marking by instructor and the students obtained feedback instantly. Other effective strategies for the organic chemistry lab include the "molecule of the week" concept (Le \& Morra, 2019) which involves (explain what this strategy is) as well as stereochemistry interactive games (da Silva Júnior, Uchoa, Sousa Lima, \& Monteiro, 2019).

\section{Experimental adaptations}

The studio-based model was shown to be effective for the introductory organic chemistry lab that typically occurs in the second year of undergraduate studies. However, for the upper year (third- and fourth-year undergraduate level) learners, understanding lab book importance through activities such as FACE may not be as effective. The advanced teaching lab focuses on starting chemistry since the very first lab period, as well as focuses learning outcomes towards students being self-sufficient. Although the way the experiments are setup are very cookbook in format which is very contrary to experience in a real chemistry lab. Often, the teaching lab does not 
properly demonstrate how to effectively find and develop synthetic procedures - a skill that the working chemist must have.

Changes in teaching approaches used specifically in the organic lab have started to gain more widespread attention in the 2010s. For instance, work by Flynn \& Biggs (2011) first tested the PBL method in a synthetic and medicinal chemistry lab course that consisted of five experiments that took multiple weeks to complete. Two experiments were taught using the standard lab manual format (traditional) and the remaining three were taught using PBL over the course of a four-month university term. An additional challenge that was observed was giving proper training of PBL to the teaching assistants (TAs) and communicating the information between TAs that had had various teaching backgrounds. The approach was to give the students a starting material (SM) and a target material (TM), but not the steps or ingredients in how to go from the SM to the TM as portrayed in Figure 4 (a) Problem section. The students must then engage themselves in self-directed learning such that they can research the literature and seek the proper outside information in order to preform the chemistry and obtain their product (Flynn \& Biggs, 2012).

The learners then had to develop a proposal that had to be approved by either the TAs or the instructor. The students then moved on to execute (Figure 4a) their experiments, where collaboration and consultation was encouraged. If the reaction failed or roadblocks were encountered, students were responsible for finding their own solutions - which often required additional research. Once students obtained the TM, they could move on to the next experiment, repeating the process.

One of the main challenges with the teaching of this material is that students did not understand that there was not a single "correct" answer. The students also had to be taught 
proper research methods and how to use chemistry specific search engines, mainly SciFinder.

Other problems and solutions are outlined in Flynn's (2011) work. However, though the amount of time and effort on the part of the facilitators and the students increases, the consensus of the students was that all students either agreed or strongly agreed that they learned more using the PBL method rather than a traditional format. Statistical findings from the end-of-term student survey are depicted in Figure $4 \mathrm{~b}$ and are indicative that even though the PBL workload was too heavy, most everyone agreed that upper year students should be required to work at this level. It can also be noted that the students were more motivated to learn using the PBL method, even though only half the students indicated they preferred the PBL method to the traditional one.

Guiding the students in an interactive and engaging manner toward solving their reactions was the key principle of this instructional approach.

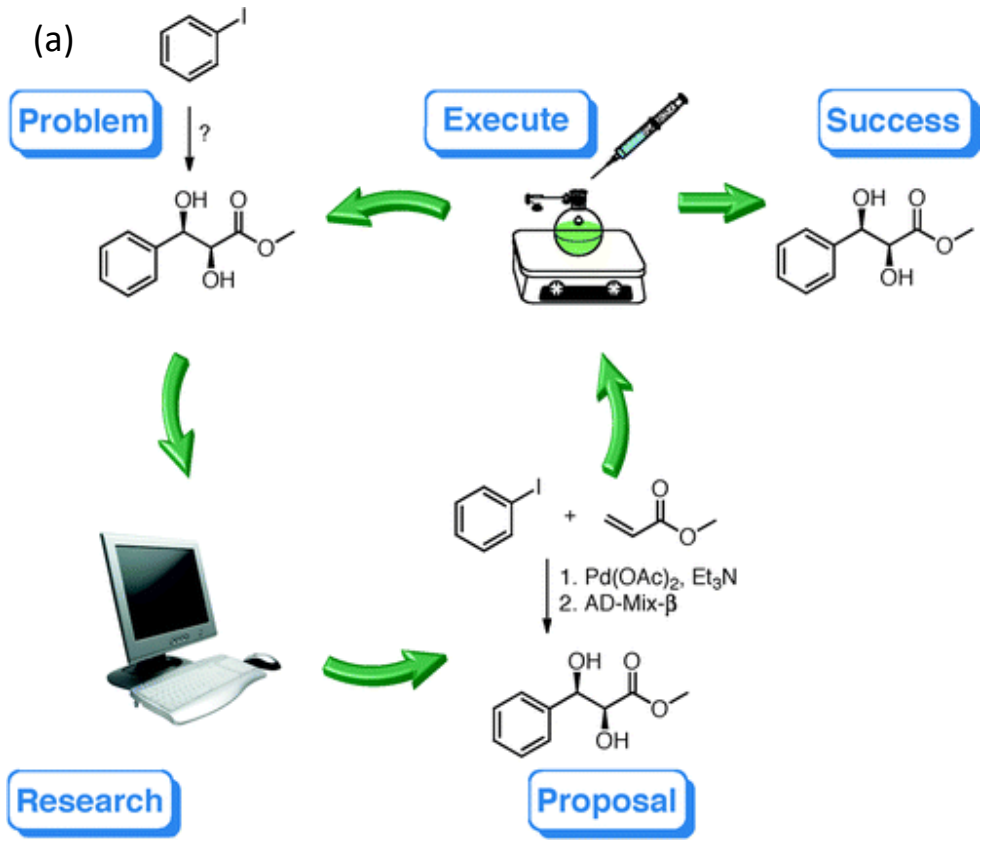

(b)

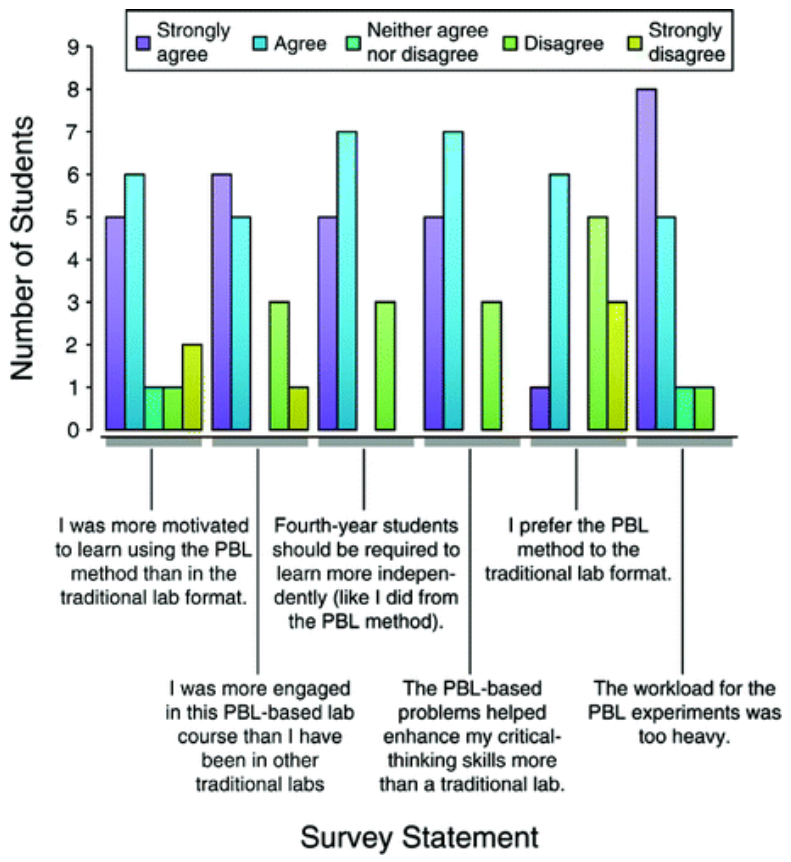

Figure 4. (a) Outline for using PBL for advanced organic chemistry teaching laboratory, (b) results from end of term student survey outlining their satisfaction with the PBL method in the lab ( $N=15)$. (Flynn \& Biggs, 2011) 
Subsequent PBL in the organic lab has followed suit. Work by Ong et al. (2018) was able to show the teaching of advanced cross-coupling reactions through using PBL towards a Sonogashira experiment. Students were given a molecule that could be produced in a single-step and had to work in groups to determine which method for the formation of the compound would be best for large-scale production, as practice for an industrial workplace setting. Further work by Zuin and co-workers (2019) has incorporated the values of sustainable chemistry in the teaching lab. The students conducted the Sonogashira experiment in a similar framework to Figure $4 \mathrm{a}$ with the additional challenge of looking for the best conditions. The procedure had to be considered for environmental friendless, effectiveness of the reaction (yield or amount of product obtained versus waste), the chemicals and equipment available, cost and time (Ong, Chan, \& Hoang, 2018).

The students were given three procedures from the lab manual and then they had to go out and find their own from the literature (at least one) and then be able to make a recommendation for large-scale synthesis. The students tested and adapted the procedures and dictated their reasoning. This work is a fine example of what a chemist would have to do during grad school or industrial work: find and test reactions and adapt and repeat to create the most optimal and cost-effective product. This is known as reaction optimization, and is a concept not often taught in teaching labs. Additional examples that attempt to incorporate Kolb's experiential learning principles and PBL to make for interactive lab experiences include boronic acid reactions (Roscales \& Csákÿ, 2019), dichlorocarbene additions (Thu Le, Klinkerch, \& Thamattoor, 2019) as well as covalent organic frameworks (COFs) synthetic chemistry (Mancheño et al., 2019). It is important to denote that COFs are a very hot topic in the chemistry 
field as of 2017, so to already have a PBL based undergraduate experiment developed shows great progress towards the teaching of organic lab chemistry and is very exciting.

The experimental adaptations must be carefully selected in that the reaction the students are doing is related to their course material, at the level there are learning, as well as feasible to do in the 3 to $6 \mathrm{hr}$ time frame. Allowing students to customize their lab schedule is also useful but requires additional planning as all lab materials have to be stocked for each lab section each week, but templates and guidelines are available (Monga et al., 2019). Additionally, the evaluation process for PBL can also be complex, as the student cannot solely be graded on final product since PBL emphasizes the not just the product but the process - the journey the learners have taken in order to conduct the experiments. Evaluating how students find and use outside information for PBL was shown to be challenging (Shultz \& Li, 2016). Students' abilities in information literacy and how they think about the reaction problems must be constantly and timely evaluated throughout the term, so that if there are any issues they are quickly resolved, and the student can proceed to optimal learning. Timing is also a factor, as was shown from the data in Figure 4b, as it is not desirable to overload the students with their already hectic schedules - which is where customizable lab schedules can come in (Monga et al., 2019).

\section{Outlook and Recommendations}

In summary, educational research on science teaching shows that improvements are being implemented in organic chemistry undergraduate labs to engage students and prepare them to become better chemists. Although PBL is a popular and well-established approached to teaching, it is a relatively new approach in in organic chemistry labs, as changing the traditional lab format does require additional time and effort from the instructor. The SBL method can also be 
integrated through lab activities, especially for teaching students the standard chemistry practices. In studies discussed in this paper, many students showed an increased motivation for learning by implementing these teaching techniques in the lab. Improvements in organic chemistry teaching in the laboratory are taking place and technologically advancing to prepare students to do actual reaction chemistry upon graduation. Thu Le's work (2019) on dichlorocarbene additions is specifically designed for collaboration and discovery, and upper year students can learn about the forefront of chemistry (i.e. COFs) in an interactive manner (Mancheño, 2019).

This is promising and indicates that the crisis in organic chemistry teaching is being addressed through several educational approaches. To add, students are being challenged in a way that prepares them to do chemistry in a less controlled setting, be it either in academia or industry. This helps to ensure that the students graduating from chemistry-based disciplines possess the proper cognitive abilities and have knowledge of common techniques and practices, such as keeping a proper lab book. Although there may be some instances where the workload seems immense for the instructor or TA, it bears to keep in mind that these students may one day work with their mentors from the organic labs, so proper education is instrumental for everyone. Many of the ideas represented here are recent, and activities such as FACE can be easily implemented to address critical teaching and learning problems in today's chemistry lab. Overall, the future of organic chemistry laboratory education is heading towards student-centered learning that is both stimulating and fun.

\section{Acknowledgements}

This work would not be possible without the invaluable help from Dr. Svitlana Taraban-Gordon, Senior Educational Developper and the Center for Teaching Excellence at the University of 
Waterloo, Waterloo, Ontario, Canada. This work was completed as part of the Certificate in

University Teaching program.

\section{References}

1) Carmel, J. H., Herrington, D. G., Posey, L. A., Ward, J. S., Pollock, A. M., \& Cooper, M. M. (2019). Helping Students to "Do Science": Characterizing Scientific Practices in General Chemistry Laboratory Curricula. Journal of Chemical Education, 96(3), 423434. doi:10.1021/acs.jchemed.8b00912

2) Chaytor, J. L., Al Mughalaq, M., \& Butler, H. (2017). Development and Use of Online Prelaboratory Activities in Organic Chemistry To Improve Students' Laboratory Experience. Journal of Chemical Education, 94(7), 859-866. doi:10.1021/acs.jchemed.6b00850

3) Collison, C. G., Cody, J., Smith, D., \& Swartzenberg, J. (2015). Formalizing the First Day in an Organic Chemistry Laboratory Using a Studio-Based Approach. Journal of Chemical Education, 92(9), 1510-1513. doi:10.1021/acs.jchemed.5b00226

4) Connor, A., Karmokar, S., \& Whittington, C. (2015). From STEM to STEAM: Strategies for Enhancing Engineering \& Technology Education. 5(2), 37-47. http://dx.doi.org/10.3991/ijep.v5i2.4458

5) da Silva Júnior, J. N., Uchoa, D. E. d. A., Sousa Lima, M. A., \& Monteiro, A. J. (2019). Stereochemistry Game: Creating and Playing a Fun Board Game To Engage Students in Reviewing Stereochemistry Concepts. Journal of Chemical Education, 96(8), 1680-1685. doi:10.1021/acs.jchemed.8b00897

6) Domin, D. S. (1999). A Content Analysis of General Chemistry Laboratory Manuals for Evidence of Higher-Order Cognitive Tasks. Journal of Chemical Education, 76(1), 109. doi:10.1021/ed076p109

7) Flynn, A. B., \& Biggs, R. (2012). The Development and Implementation of a ProblemBased Learning Format in a Fourth-Year Undergraduate Synthetic Organic and Medicinal Chemistry Laboratory Course. Journal of Chemical Education, 89(1), 52-57. doi:10.1021/ed101041n

8) Fung, F. M., \& Watts, S. F. (2019). Bridges to the Future: Toward Future Ready Graduates in Chemistry Laboratories. Journal of Chemical Education, 96(8), 1620-1629. doi:10.1021/acs.jchemed.8b00771

9) Herreid, C. F. (1997). What is a case. Journal of College Science Teaching, 27(2). http://sciencecases.lib.buffalo.edu/cs/pdfs/What\%20is\%20a\%20Case-XXVII-2.pdf

10) Kulak, V., \& Newton, G. (2014). A guide to using case-based learning in biochemistry education. Biochemistry and Molecular Biology Education, 42(6), 457-473. doi:10.1002/bmb.20823

11) Latimer, D. R., Ata, A., Forfar, C. P., Kadhim, M., McElrea, A., \& Sales, R. (2018). Overcoming the Hurdle from Undergraduate Lab to Research Lab: A Guided-Inquiry Structural Characterization of a Complex Mixture in the Upper-Division Undergraduate 
Organic Lab. Journal of Chemical Education, 95(11), 2046-2049.

doi:10.1021/acs.jchemed.7b00421

12) Le, C. M., \& Morra, B. (2019). Using Retrosynthetic Graphic Organizers and Molecule of the Week Activities in Organic Chemistry Tutorials. Journal of Chemical Education, 96(8), 1640-1645. doi:10.1021/acs.jchemed.8b00970

13) Mancheño, M. J., Royuela, S., de la Peña, A., Ramos, M., Zamora, F., \& Segura, J. L. (2019). Introduction to Covalent Organic Frameworks: An Advanced Organic Chemistry Experiment. Journal of Chemical Education, 96(8), 1745-1751. doi:10.1021/acs.jchemed.8b00810

14) Monga, V., Knox, K. J., Gillis, E. A. L., Stoodley, R., Bussiere, G., \& Rogers, C. (2019). Implementation of a Student-Customized Integrated Upper-Level Chemistry Laboratory Course. Journal of Chemical Education, 96(8), 1609-1619. doi:10.1021/acs.jchemed.8b00815

15) Moozeh, K., Farmer, J., Tihanyi, D., Nadar, T., \& Evans, G. J. (2019). A Prelaboratory Framework Toward Integrating Theory and Utility Value with Laboratories: Student Perceptions on Learning and Motivation. Journal of Chemical Education, 96(8), 15481557. doi:10.1021/acs.jchemed.9b00107

16) Norman, G. R., \& Schmidt, H. G. (2000). Effectiveness of problem-based learning curricula: theory, practice and paper darts. Medical Education, 34(9), 721-728. doi:10.1046/j.1365-2923.2000.00749.x

17) Ong, J.-Y., Chan, S.-C., \& Hoang, T.-G. (2018). Empowering Students To Design and Evaluate Synthesis Procedures: A Sonogashira Coupling Project for Advanced Teaching Lab. Journal of Chemical Education, 95(6), 1078-1081. doi:10.1021/acs.jchemed.7b00522

18) Popova, M., \& Bretz, S. L. (2018). "It's Only the Major Product That We Care About in Organic Chemistry": An Analysis of Students' Annotations of Reaction Coordinate Diagrams. Journal of Chemical Education, 95(7), 1086-1093. doi:10.1021/acs.jchemed.8b00153

19) Reid, N., \& Shah, I. (2007). The role of laboratory work in university chemistry. Chemistry Education Research and Practice, 8(2), 172-185. doi:10.1039/B5RP90026C

20) Roscales, S., \& Csákÿ, A. G. (2019). Synthesis of Flufenamic Acid: An Organic Chemistry Lab Sequence Using Boronic Acids and Nitrosoarenes under TransitionMetal-Free Conditions. Journal of Chemical Education, 96(8), 1738-1744. doi:10.1021/acs.jchemed.8b00824

21) Russell, C. B., Mason, J. D., Bean, T. G., \& Murphree, S. S. (2014). A Student-Centered First-Semester Introductory Organic Laboratory Curriculum Facilitated by MicrowaveAssisted Synthesis (MAOS). Journal of Chemical Education, 91(4), 511-517. doi:10.1021/ed400064f

22) Santos-Díaz, S., Hensiek, S., Owings, T., \& Towns, M. H. (2019). Survey of Undergraduate Students' Goals and Achievement Strategies for Laboratory Coursework. Journal of Chemical Education, 96(5), 850-856. doi:10.1021/acs.jchemed.8b00984 
23) Shultz, G. V., \& Li, Y. (2016). Student Development of Information Literacy Skills during Problem-Based Organic Chemistry Laboratory Experiments. Journal of Chemical Education, 93(3), 413-422. doi:10.1021/acs.jchemed.5b00523

24) Szu, E., Nandagopal, K., Shavelson, R. J., Lopez, E. J., Penn, J. H., Scharberg, M., \& Hill, G. W. (2011). Understanding Academic Performance in Organic Chemistry. Journal of Chemical Education, 88(9), 1238-1242. doi:10.1021/ed900067m

25) Thu Le, N. N., Klinkerch, E. J., \& Thamattoor, D. M. (2019). Stereochemistry of Dichlorocarbene Addition to Alkenes: A Collaborative, Discovery-Based Experiment for the Organic Chemistry Laboratory. Journal of Chemical Education, 96(8), 1727-1730. doi:10.1021/acs.jchemed.8b00758

Supporting literature not referred directly in text:

1) Galloway, K. R., \& Bretz, S. L. (2015). Measuring Meaningful Learning in the Undergraduate General Chemistry and Organic Chemistry Laboratories: A Longitudinal Study. Journal of Chemical Education, 92(12), 2019-2030. doi:10.1021/acs.jchemed.5b00754

2) Glover, S. R., Sewry, J. D., Bromley, C. L., Davies-Coleman, M. T., \& Hlengwa, A. (2013). The Implementation of a Service-Learning Component in an Organic Chemistry Laboratory Course. Journal of Chemical Education, 90(5), 578-583.

doi:10.1021/ed2008153 